\title{
Cross-Sectional Study of Mandibular Canal Branching in Regions Affected by Dental Inflammation with Cone Beam Computed Tomography
}

\author{
Estudio Transversal de la Ramificación del Canal Mandibular en Regiones Afectadas \\ por Inflamación Dental con Tomografía Computarizada de Haz Cónico
}

\author{
Mauricio Augusto Aquino de Castro'; Manuel Oscar Lagravere Vich; \\ Mauro Henrique Guimaraes Abreu ${ }^{3}$ \& Ricardo Alves Mesquita ${ }^{4}$
}

DE CASTRO, M. A. A.; VICH, M. O. L.; ABREU, M. H. G. \& MESQUITA, R. A. Cross-sectional study of mandibular canal branching in regions affected by dental inflammation with cone beam computed tomography. Int. J. Odontostomat., 13(2):142149, 2019.

ABSTRACT: The present study aimed to investigate the occurrence of mandibular canal alterations in regions with dental inflammation by means of cone beam computed tomography (CBCT). A database of 2,484 CBCTs was reviewed for identifying dental inflammation in mandibular alveolar ridges. The final sample consisted of $150 \mathrm{CBCTs}$, including 91 females and 59 males, with ages ranging from 13 to 89 years (mean age of 47.06 ; $\pm S D=18.722$ ). The presence and location of dental inflammation, gender, age, as well as presence and location of mandibular canal branching (MCB) were evaluated. The Kolmogorov-Smirnov, Chi-square, and T-test were applied to verify the statistical relationship of the data. There were 178 images of dental inflammation on 150 CBCTs, mainly located at molars' region (75\%). Apical lesions were the most common type of dental inflammation found (79 or $44.4 \%$ of the sample), followed by pericoronitis (32; $18.0 \%)$. This study identified 135 mandibular canal branches in the exams that presented dental inflammation. The MCB were also most commonly located at molars' region $(74.07 \%)$. No statistical difference was identified regarding the distribution of mandibular canal branching in relation to the sites with dental inflammation $(p=0.370)$. The MCB found were mostly single $(86$ or $63.7 \%$ of the total). Sex had no influence on mandibular canal branching occurrence $(p=0.308)$, not did age $(p=0.728)$. A high prevalence of mandibular canal branching was observed in the regions where dental inflammation were identified, most commonly found in the molar region.

KEY WORDS: radiology, diagnosis, clinical assessment, cone beam computed tomography, inferior alveolar nerve, mandibular canal.

\section{INTRODUCTION}

Neurovascular branching in the mandibular region is a normal morphological variation and may occur with the inferior alveolar and mylohyoid nerves. According Wilson et al. (1984) the inferior alveolar neurovascular bundle is responsible for innervation and blood supply to mandibular structures. It enters into the mandibular canal, a usually unique intraosseous canal in each hemi-mandible.

Variations of the mandibular canal pathways were named bifid or trifid canals and related to malformations occurred during embryonic period by Chávez-Lomeli et al. (1996). Rodella et al. (2012) verified that their location and prevalence vary depending on the type of diagnostic test used. On panoramic X-rays these were located in the ramus region with prevalence varying from $0.08 \%$ to $16.8 \%$. When using three-dimensional images (3D) they were also located in the ramus region, with higher prevalence up to $65 \%$, according Naitoh et al. (2009).

Castro et al. (2015) verified classifications of these anatomical variations and detected that they were performed mainly based on two-dimensional exams

\footnotetext{
${ }^{1}$ Department of Dentistry, Federal University of Juiz de Fora / Campus Governador Valadares - Brazil.

2 Orthodontic Program, University of Alberta - Canada. Edmonton, Canada.

${ }^{3}$ Community and Preventive Dentistry Department, Federal University of Minas Gerais - Brazil.

${ }^{4}$ Oral Surgery and Pathology Department, Federal University of Minas Gerais - Brazil.
} 
(2D). Since 3D imaging has presented a higher sensitivity in identifying bifid and trifid canals in the ramus region, some features related to their direction were additionally reported by Rouas et al. (2007); Neves et al. (2010); Fukami et al. (2012); Muinelo-Lorenzo et al. (2014). Despite the method, the classifications of Nortjé et al. (1977); Langlais et al. (1985); Naitoh et al., and Muinelo-Lorenzo et al. are usually related to location, number, and direction

It is clinically important to know morphological variations of the mandibular canal in order to avoid harmful complications that may occur during several surgical procedures, such as implant placement, harvesting of bone grafts, extraction of impacted teeth, apical surgeries, bilateral sagittal split osteotomies, and pathology enucleating, as warned by Juodzbalys et al. (2011) and Mizbah et al. (2012). The presence of neurovascular branches derived from the main inferior alveolar bundle within bifid canals was already proved by Fukami et al. González-Santana et al. (2005) reported relevant prevalence of postoperative neuropathic pain related to inferior alveolar nerve injuries occurred during surgical procedures.

Morphological variations of the mandibular canal were also related to sensory alterations in mandibles by González-Santana et al., Juodzbalys et al., Rodella et al., Mizbah et al. and Corbella et al. (2017). Painful symptoms and difficulties with anesthetic procedures were increased on mandibular alveolar ridges affected by dental inflammation. Additionally to action of endogenous inflammatory factors delivered by dental inflammation and related to pain, neurovascular variations may be also related to increased sensitivity in mandibles, according Potocnik \& Bajrovic (1999), Li et al. (2012), and Corbella et al. It has been difficult to determine the true role of the inflammation in relation to supplementary innervation in these situations. Clinical interaction between dental inflammation and nerve alterations was already identified by Najjar (1977) even when the inflammation site was relatively far from the neurovascular alteration. The influence of inflammatory mediators on dorsal root regeneration of spinal cords of rats proved by Di Maio et al. (2011), and the neurogenesis in human intervertebral discs demonstrated by Lee et al. (2011) are scientific evidences of the relationship between inflammation and neurovascular alterations.

Considering the risk of neurovascular injuries and sensory disturbances related anatomical variations of the inferior alveolar nerve, the purpose of the present study was to search for some evidence of similar phenomena in mandibles. The mandibular canal was assessed in alveolar ridges affected by dental inflammation using a large sample of CBCT at two different oral radiology centers from Brazil and Canada.

An evidence of association between dental inflammation and MCB can be useful for improving the knowledge about inflammatory effects in mandibles, avoiding neurovascular injury and sensory alterations after surgical procedures, by previewing the occurrence of this anatomical variation. Besides that, it will stimulate future researches about inflammatory process responsible for stimulating such neurovascular response.

\section{MATERIAL AND METHOD}

The present study is in full accordance with ethical principles, including the World Medical Association Declaration of Helsinki . Approval in research ethics from the Federal University of Minas Gerais (UFMG) (Brazil - COEP 432.2982) and the University of Alberta (Canada - Pro00050422), including informed consent from each patient, were obtained.

Mandibular CBCTs were obtained from the database of a private diagnostic imaging center (Hermes Pardini Institute - Belo Horizonte, Brazil) and from the University of Alberta's Department of Dentistry database. The images were taken for diagnostic and medical purposes, as requested by the patients' clinicians. This study retrospectively assessed a set of 2,484 CBCTs, 1,307 from the Brazilian and 1,177 from the Canadian center.

CBCTs were obtained from I-CAT® (Next Generation Model - Imaging Sciences International Hatfield, PA, USA). The Brazilian scans were acquired using a voxel size of $0.25 \mathrm{~mm}$, a field of view of $7 \times 16$ $\mathrm{cm}$, and an exposure time of 26.9 seconds (120kV; $3-$ $7 \mathrm{~mA}$ ). The Canadian scans were acquired with a voxel size of $0.3 \mathrm{~mm}$, a field of view of $13 \times 16 \mathrm{~cm}$, and an exposure time of 8.9 seconds $(120 \mathrm{kV} ; 3-7 \mathrm{~mA})$. The images were analyzed by creating panoramic views (5.25 to $10.25 \mathrm{~mm}$ in thickness) and multiplanar sectional slices $(1 \mathrm{~mm}$ in thickness and $1 \mathrm{~mm}$ in spacing), using the Xoran ${ }^{\circledR}$ software (Xoran Technologies - Ann Arbor, MI, USA). Different voxel 
sizes were due to different clinical requirements for imaging. The T-test for independent samples was used to verify their diagnostic accuracy of mandibular canal branching. The result showed a homogeneity of variance that was statistically significant $(p=0.122)$. Thus, the different voxel sizes had no influence on the detection of MCB.

Assessments were performed using a 20" LED monitor with a $1600 \times 900$ pixel resolution (Flatron E2442TC model - LG Electronics - Seoul, South Korea). Intra-examiner reliability was performed analyzing 20 randomly selected CBCTs three times, with 15 day intervals between each evaluation trial. The Kappa test was used to determine intra-examiner reliability, and almost perfect agreement for the detection of the ramifications was found (.842).

The 2,484 CBCTs were analyzed for the presence of dental inflammation in the posterior region of the mandibular alveolar ridge, at the molar and premolar regions. The detection of dental inflammation was performed along with the review of the clinical charts of the patients who had CBCTs taken. The dental inflammations were confirmed in the CBCTs and were considered to be: 1) bone lesion-like radiolucency located adjacent to the root tips, with endodontic origin; 2) osteolysis surrounding the roots, which represented combined periodontal and endodontic lesions; 3) vertical and/or horizontal bone loss, representing advanced periodontal disease; 4) osteolysis surrounding implants, diagnosed as peri-implantitis; 5) sites of external inflammatory root resorption, concomitantly with adjacent radiolucency, representing osteolysis; 6) thickening of the periodontal attachment, presenting an additional sign of pericementitis, and/or 7) pericoronal space thickening of the impacted teeth, as an additional sign of pericoronitis. Exams without signs of dental inflammations were not included in the study.

The following variables were recorded in a spreadsheet: gender, age, presence and location of dental inflammation, and mandibular canal branching. Age was dichotomized by its median in order to verify whether or not there would be differences between mandibular canal branching and the age groups (younger or older individuals).

The MCB location was defined as the site where the branches emerged from the mandibular canal. The locations were: 1) ramus (region between the mandibular foramen and the anterior edge of the ramus); 2) retromolar (between the anterior edge of the ramus and the distal surface of the third molar); 3 ) molar (region between the first and third molars); 4) premolar region (region of the first and second premolars). In cases of advanced periodontal disease with horizontal bone loss, the entire mandible was considered as the location. The total number of MCB in each patient and the proximity between the dental inflammation and the branches were also analyzed.

According their features, the $\mathrm{MCB}$ were classified as: 1) number: single, double, or multiple, considering their number after arising from the mandibular canal; 2) orientation: upper, inferior, vestibular, or lingual, according to their direction after arising from the mandibular canal; 3) connection with dental inflammations: when terminations had contact or not with the dental inflammation; and 4) classified according with the location of connection with dental roots on apical, medium, or cervical thirds.

The statistical analysis was performed using the Statistical Package for Social Sciences (SPSS - 21.0, IBM, Armonk, NY, USA), with the significance level set to $5 \%(P<0.05)$. The Kolmogorov Smirnov test was used to verify the distribution of the sample, and the Ttest, Chi-square test, or Fisher Exact tests were used to assess the statistical differences between the occurrence of MCB and the variables.

The present cross-sectional study is in compliance with the strengthening the reporting of observational studies in epidemiology (STROBE) statement, according von Elm et al. (2007).

\section{RESULTS}

This study identified 150 patients that presented dental inflammation, of whom 91 females and 59 males, with ages ranging between 13 and 89 years (mean age of 47.06; $\pm S D=18.722$ ). The final sample consisted of 178 images of dental inflammation, taking into account both sides of each patient. Twenty-four patients presented two images of dental inflammations, and one patient presented three images. The dental inflammations were mainly found in the molars region $(75.3 \%)$, and $24.7 \%$ located in the premolar region.

There were 135 MCB among the 178 images that presented dental inflammation $(75.8 \%)$. No statistically significant difference was found regarding gender $(p=0.308)$ and mean age $(p=0.077)$ for the 
occurrence of the branches. The sample's median age was 50 years; $50.37 \%$ of the MCB occurred in patients of up to 50 years of age and $49.63 \%$ in older patients. The T-test showed that there was homogeneity of variance of the MCB statistically significant $(p=0.728)$ when comparing the groups (up to 50 years old and older patients).

The MCB was most commonly located in the molar regions $(74.07 \%$ of the MCB). The premolar regions presented $22.2 \%$ of the branches (Table I). No statistically significant difference between the locations of dental inflammation and MCB was observed (Table II).

The MCB found were mostly single (86 or 63.7 $\%$ of the total). There were also 28 double branches $(20.7 \%)$ and 21 multiple branches $(15.6 \%$ of the total). The most common direction of the branches after arising from the mandibular canal was toward upper region (126 or $93.4 \%$ ) (Figs. $1 \mathrm{~A}, \mathrm{~B})$. This study also found three branches stemming in the lingual direction $(2.2 \%)$, three in the vestibular direction $(2.2 \%)$, and three toward posterior region (2.2 \%) (Fig. 2).
Considering the 135 exams that presented MCB, the number of branches and their directions were compared. No difference between the number frequencies and their directions were observed $(p=$ 0.608) (Table III).

This study detected $97 \mathrm{MCB}$ in contact with dental inflammation $(71.8 \%$ of the MCB and $54.5 \%$ of the dental inflammations). The connections occurred on the region of the apical third of the roots (37.0\%) (Fig. $1 \mathrm{~B})$, on the medium third (20.0\%) (Fig. 1A), or on the cervical third (14.8\%) (Fig. 2); $28.2 \%$ of the MCB did not come into contact with dental inflammations.

When analyzing just the exams with $\mathrm{MCB}$, the apical lesions (Fig.s $1 \mathrm{~A}$ and $1 \mathrm{~B}$ ) were the most common type found (59 or $43.7 \%$ ), followed by pericoronitis (29 or $21.5 \%$ ). Combined endodontic-periodontal lesions were the third most common and were present in 20 scans (14.8\%). There were also 13 cases with periodontal bone loss (9.6\%), 10 cases with signs of pericementitis $(7.4 \%), 03$ cases presenting perimplantitis (2.2\%) (Fig. 3), and 01 with inflammatory root resorption $(0.7 \%)$.

Table I. Distribution of mandibular canal branches per region $(\mathrm{N}=135)$.

\begin{tabular}{cccccccc}
\hline & \multicolumn{4}{c}{ Rranches } \\
& Right side & \multicolumn{3}{c}{ Left side } \\
& $\begin{array}{c}\text { Ramus } / \\
\text { Retromolar }\end{array}$ & Molar & Premolar & Premolar & Molar & $\begin{array}{c}\text { Ramus / } \\
\text { Retromolar }\end{array}$ & Total \\
\hline $\begin{array}{c}\text { Number } \\
(\%)\end{array}$ & 02 & 52 & 17 & 13 & 48 & 03 & 135 \\
& $(1.5 \%)$ & $(38.5 \%)$ & $(12.6 \%)$ & $(9.6 \%)$ & $(35.6 \%)$ & $(2.2 \%)$ & $(100 \%)$ \\
\hline
\end{tabular}

Table II. Distribution of mandibular canal branching in relation to dental inflammation locations.

\begin{tabular}{lccc}
\hline & \multicolumn{2}{c}{ Mandibular canal branching } & \\
Location of dental inflammation & No & Yes & P value* $^{*}$ \\
\hline Premolars & $6(16.7 \%)$ & $30(83.3 \%)$ & \\
Molars & $34(25.4 \%)$ & $100(74.6 \%)$ & 0.370 \\
Ramus/Retromolar & $3(37.5 \%)$ & $5(62.5 \%)$ & \\
\hline${ }^{*}$ Pearson Chi-square Test & &
\end{tabular}

Table III. Distribution between locations of dental inflammations and mandibular canal branches.

\begin{tabular}{|c|c|c|c|}
\hline \multirow[b]{2}{*}{ Mandibular canal branching } & \multicolumn{2}{|c|}{$\begin{array}{l}\text { Number of mandibular canal } \\
\text { branching }\end{array}$} & \multirow[b]{2}{*}{$P$ value* } \\
\hline & Single & Double or multiple & \\
\hline Lingual & $3(100 \%)$ & $0(0 \%)$ & \\
\hline Superior & $80(63.5 \%)$ & $46(36.5 \%)$ & 0.608 \\
\hline Vestibular & $1(33.3 \%)$ & $2(66.7 \%)$ & \\
\hline Posterior & $2(66.7 \%)$ & $1(33.3 \%)$ & \\
\hline
\end{tabular}

\footnotetext{
* Fisher Exact Test.
} 


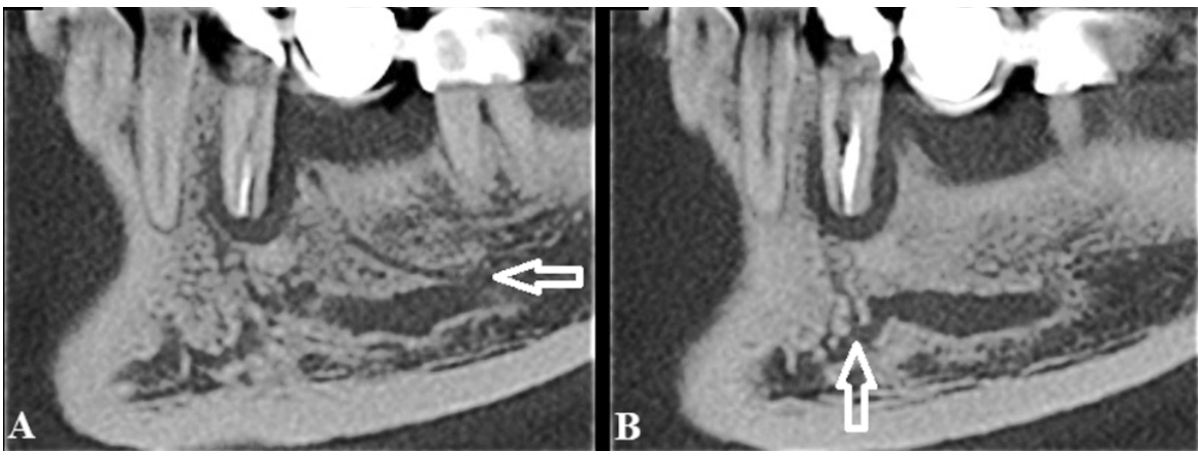

Fig. 1 A. Single, superior and medium third mandibular canal branch toward apical lesion of tooth 35 (white arrows);

1B: Single, superior and apical mandibular canal branch (white arrows) toward apical lesion of tooth 35 .

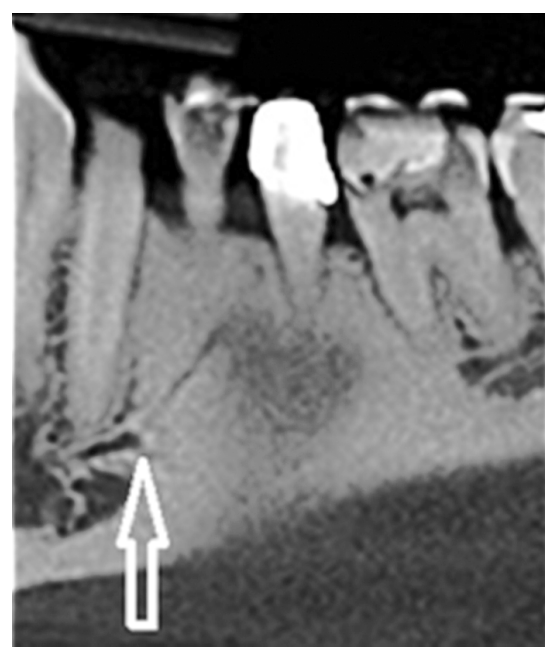

Fig. 2. Single, posterior and cervical mandibular canal branch (white arrow) toward horizontal bone loss.

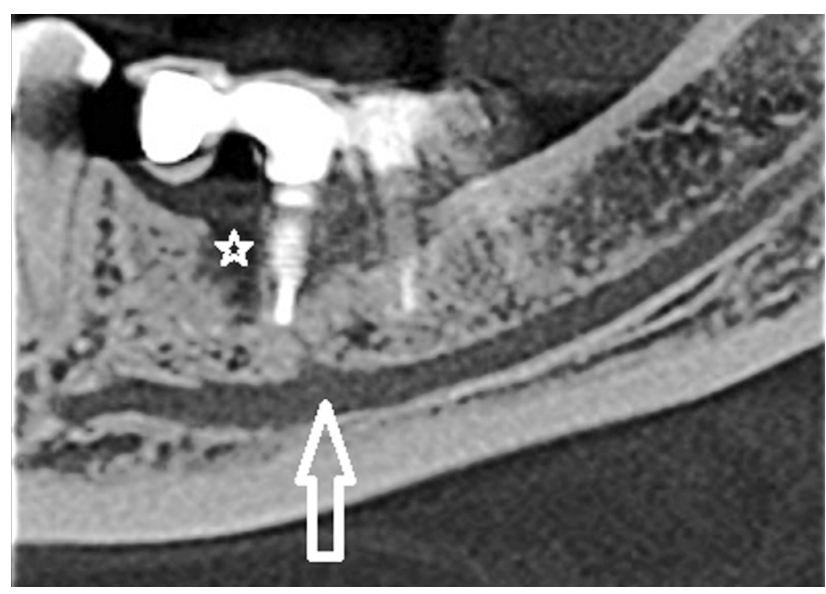

Fig 3. Double, superior and apical mandibular canal branch (white arrow) toward perimplantitis (white star).

\section{DISCUSSION}

Aiming to observe if there would be some alteration of the mandibular canals in mandibles affected by dental inflammation, the present study assessed 2,484 CBCTs. The main finding of this study was the high prevalence of MCB in regions with dental inflammations, without statistically significant differences. This is a novelty since no previous study has considered a post natal physiologic process as a variable related with $\mathrm{MCB}$, such as inflammatory dental lesions.

The dental inflammations were mainly found in the molar region, with apical lesions representing the most commonly found type of inflammation. These findings are in accordance with Awad (2013) which identified apical cysts and granulomas as the most common lesions affecting the jaw, with the largest proportion located in the posterior regions.
No statistically significant differences of the occurrence of MCB could be observed with relation to patient age or gender. This finding is in accordance with Nortjé et al., whom also did not find any correlation between mandibular canal variations and age or gender after evaluation of 3,612 panoramic radiographs. Same results were observed in studies of Naitoh et al. and Orhan et al. (2013) that assessed bifid canals in CBCT exams, although they had not considered dental inflammation as a variable.

The MCB found were mostly single and directed to the upper region, similar to dental branches previously reported by Naitoh et al. But they are not the same, given that the MCB identified in the present study were consistently toward dental inflammation. The single and upper MCB often ran toward dental inflammations, coming in contact with them, and usually 
DE CASTRO, M. A. A.; VICH, M. O. L.; ABREU, M. H. G. \& MESQUITA, R. A. Cross-sectional study of mandibular canal branching in regions affected by dental inflammation with cone beam computed tomography. Int. J. Odontostomat., 13(2):142-149, 2019.

far from the root tips. In addition, they presented different patterns, such as double or multiple branches, or even some posteriorly oriented. The Figure 3 illustrates an example of a different pattern, showing a case of a MCB toward peri-implant lesion.

Regarding the previous classifications, it is important to highlight an additional issue about branches' location. Most of MCB found in the present study emerged around dental inflammatory lesions in the posterior region of the alveolar ridges, named molar or premolar regions. Since the existent classifications of Nortjé et al., Langlais et al., Naitoh et al., and Muinelo-Lorenzo et al. were referred to bifid canals that emerged in the ramus region, they were not adopted by the present study.

The large number of MCB linked to dental inflammations reinforces the suspicion of a relationship between inflammation and neurovascular alterations. This feature is similar to prior scientific evidences of nerve alterations related to inflammatory response demonstrated by Di Maio et al., and Lee et al. Since any other study on bifid mandibular canals has considered a post natal physiologic process as a possible factor associated with nerve alterations, their findings cannot be used for comparing the peculiar occurrence, location, and features reported in the present study.

One doubt that could arise would be related the possibility of MCB containing only blood vessels, representing a common vascular alteration associated with inflammatory response. Although just a vascular alteration may represent a potential risk of significant bleeding during surgical procedures, Neves et al. have already stated that the imaging assessment of morphological variations of the mandibular canal assumes the presence of the inferior alveolar neurovascular bundle, due to its origin. In addition, histological investigation of Fukami et al. detected both vascular and neuronal components in the mandibular canal branches, representing a real risk of neurovascular injury.

The occurrence of supplementary innervation is considered a hypothesis for increased painful symptoms and difficulties with anesthetic procedures on alveolar ridges affected by dental inflammation by the authors Najar, Wilson et al., Potocnik \& Bajrovic', Corbella et al., and Li et al. In this sense, the MCB can be contributing for this clinical adverse situation. Adding this question to increased risk of neurovascular injuries related to morphological variations, the occurrence of MCB must be considered by clinicians when planning surgical procedures and anesthetic procedures on mandibles that have been previously affected by dental inflammations.

According to the American Academy of Oral and Maxillofacial Radiology statement by Tyndall et al., (2012), the CBCT exam is currently the main imaging modality for detecting mandibular canals and their variations. The CBCT is really highly sensitive and it is clear that the detection of $\mathrm{MCB}$ was improved by the method used in this study. The diagnosis of this important anatomical variation is crucial when planning several dental procedures, including implant insertions, harvesting of bone grafts, apical surgeries, extractions of non-erupted teeth, as well as other surgical procedures as studied by González-Santana et al., Juodzbalys et al., and Myzbah et al.

Therefore MCB seems to be derived from inflammatory phenomena the study presents a limitation. The MCBs may be a kind of preexisting canal that have not been previously detected or classified, and their location at the same sites with dental inflammatory lesions can be just a coincidence. Nevertheless, no prior description of MCB located in the mandibular bodies has been adequately presented in the literature, as well as such high simultaneous prevalence of MCB and dental inflammation. Thus, the MCB located in the mandibular bodies as well as its high prevalence at the same sites with dental inflammations are findings no previously detected.

There are similar findings of Di Maio et al., and Lee et al. in other structures of the human body that can help to explain sensory alterations of mandibles affected by inflammation. We hope the presented evidences open new perspectives and stimulate researches about the relationship between inflammation and neurovascular alterations. The improvement of the surgical planning, reduction on prevalence of post-surgical sensitivity and the creation of therapies for repairing neurovascular injuries are expected goals of these initial findings. Epidemiological researches such as case-control and cohort studies, in addition to molecular studies about inflammatory endogenous factors related to neurovascular alterations can provide further advances. 
DE CASTRO, M. A. A.; VICH, M. O. L.; ABREU, M. H. G. \& MESQUITA, R. A. Estudio transversal de la ramificación del canal mandibular en regiones afectadas por inflamación dental con tomografía computarizada de haz cónico. Int. J. Odontostomat.,13(2):142-149, 2019.

RESUMEN: El presente estudio tuvo como objetivo investigar la ocurrencia de ramificación del canal mandibular (RCM) en regiones con inflamación dental mediante tomografía computarizada de haz cónico (TCHC). Se revisó una base de datos de $2.484 \mathrm{TCHC}$ para identificar la inflamación dental en las crestas alveolares mandibulares. La muestra final consistió en $150 \mathrm{TCHC}$, incluidas 91 mujeres y 59 hombres, con edades comprendidas entre 13 y 89 años (edad media de 47,06 $\pm \mathrm{DE}=18,722$ ). Se evaluaron el sexo, la edad, la presencia y la ubicación de la inflamación dental, así como la presencia y ubicación de RCM. KolmogorovSmirnov, Chi-cuadrado y prueba-T se aplicaron para verificar la relación estadística de los datos. Hubo 178 imágenes de inflamación dental en 150 TCHC, ubicados principalmente en la región de los molares (75\%). Las lesiones apicales fueron el tipo más común de inflamación dental encontrada ( 79 o $44,4 \%$ de la muestra), seguidas por pericoronitis (32; $18,0 \%$ ). Este estudio identificó 135 ramas del canal mandibular en las regiones que presentaron inflamación dental. El RCM también se localizó con mayor frecuencia en la región de los molares $(74,07 \%)$. No se identificaron diferencias estadísticas con respecto a la distribución de la ramificación del canal mandibular en relación con los sitios con inflamación dental $(p=0,370)$. Las RCM encontrados fueron en su mayoría solteros (86 o $63,7 \%$ del total). El sexo no tuvo influencia en la ocurrencia de la ramificación del canal mandibular $(p=0,308)$, no la edad $(p=0,728)$. Se observó una alta prevalencia de ramificación del canal mandibular en las regiones donde se identificó la inflamación dental, que se encuentra con mayor frecuencia en la región molar.

PALABRAS CLAVE: radiología, diagnóstico, evaluación clínica, tomografía computarizada del haz cónico, nervio alveolar inferior, canal mandibular.

\section{REFERENCES}

Awad, M. A. Most radiolucent lesions of the jaw are classified as granulomas and cysts in a U.S. population. J. Evid. Based Dent. Pract., 13(2):70-1, 2013.

Castro, M. A.; Lagravere-Vich, M. O.; Amaral, T. M.; Abreu, M. H. \& Mesquita, R. A. Classifications of mandibular canal branching: A review of literature. World J. Radiol., 7(12):531-7, 2015.

Chávez-Lomeli, M. E.; Mansilla Lory, J.; Pompa, J. A. \& Kjaer, I. The human mandibular canal arises from three separate canals innervating different tooth groups. J. Dent. Res., 75(8):15404, 1996.

Corbella, S.; Taschieri, S.; Mannocci, F.; Rosen, E.; Tsesis, I. \& Del Fabbro, M. Inferior alveolar nerve block for the treatment of teeth presenting with irreversible pulpitis: A systematic review of the literature and meta-analysis. Quintessence Int., 48(1):6982, 2017.

Di Maio, A.; Skuba, A.; Himes, B. T.; Bhagat, S. L.; Hyun, J. K.; Tessler, A.; Bishop, D. \& Son, Y. J. In vivo imaging of dorsal root regeneration: rapid immobilization and presynaptic differentiation at the CNS/PNS border. J. Neurosci., 31(12):4569-82, 2011.

Fukami, K.; Shiozaki, K.; Mishima, A.; Kuribayashi, A.; Hamada, Y. \& Kobayashi, K. Bifid mandibular canal: confirmation of limited cone beam CT findings by gross anatomical and histological investigations. Dentomaxillofac. Radiol., 41(6):4605, 2012.

González-Santana, H.; Peñarrocha-Diago, M.; Guarinos-Carbó, J. \& Balaquer-Martínez, J. Pain and inflammation in 41 patients following the placement of 131 dental implants. Med. Oral Patol. Oral Cir. Bucal, 10(3):258-63, 2005.

Juodzbalys, G.; Wang, H. L. \& Sabalys, G. Injury of the inferior alveolar nerve during implant placement: a literature review. J. Oral Maxillofac. Res., 2(1):e1, 2011.

Langlais, R. P.; Broadus, R. \& Glass, B. J. Bifid mandibular canals in panoramic radiographs. J. Am. Dent. Assoc., 110(6):923-6, 1985.

Lee, J. M.; Song, J. Y.; Baek, M.; Jung, H. Y.; Kang, H.; Han, I. B.; Kwon, Y. D. \& Shin, D. E. Interleukin-1b induces angiogenesis and innervation in human intervertebral disc degeneration. $J$. Orthop. Res., 29(2):265-9, 2011.

Li, C.; Yang, X.; Ma, X.; Li, L. \& Shi, Z. Preoperative oral nonsteroidal anti-inflammatory drugs for the success of the inferior alveolar nerve block in irreversible pulpitis treatment: a systematic review and meta-analysis based on randomized controlled trials. Quintessence Int., 43(3):209-19, 2012.

Mizbah, K.; Gerlach, N.; Maal, T. J.; Bergé, S. J. \& Meijer, G. J. The clinical relevance of bifid and trifid mandibular canals. Oral Maxillofac. Surg., 16(1):147-51, 2012.

Muinelo-Lorenzo, J.; Suárez-Quintanilla, J. A.; Fernández-Alonso, A.; Marsillas-Rascado, S. \& Suárez-Cunqueiro, M. M. Descriptive study of the bifid mandibular canals and retromolar foramina: cone beam CT vs panoramic radiography. Dentomaxillofac. Radiol., 43(5):20140090, 2014.

Naitoh, M.; Hiraiwa, Y.; Aimiya, H. \& Ariji, E. Observation of bifid mandibular canal using cone-beam computerized tomography. Int. J. Oral Maxillofac. Implants, 24(1):155-9, 2009.

Najjar, T. A. Why Why can't you achieve adequate regional anesthesia in the presence of infection? Oral Surg. Oral Med. Oral Pathol., 44(1):7-13, 1977

Neves, F. S.; Torres, M. G.; Oliveira, C.; Campos, P. S. \& CrusoéRebello, I. Lingual accessory mental foramen: a report of an extremely rare anatomical variation. J. Oral Sci., 52(3):501-3, 2010.

Nortjé, C. J.; Farman, A. G. \& Grotepass, F. W. Variations in the normal anatomy of the inferior dental (mandibular) canal: a retrospective study of panoramic radiographs from 3612 routine dental patients. Br. J. Oral Surg., 15(1):55-63, 1977.

Orhan, A. I.; Orhan, K.; Aksoy, S.; Ozgül, O.; Horasan, S.; Arslan, A. \& Kocyigit, D. Evaluation of perimandibular neurovascularization with accessory mental foramina using cone-beam computed tomography in children. J. Craniofac. Surg., 24(4):e365-9, 2013.

Potocnik, I. \& Bajrovic, F. Failure of inferior alveolar nerve block in endodontics. Endod. Dent. Traumatol., 15(6):247-51, 1999.

Rodella, L. F.; Buffoli, B.; Labanca, M. \& Rezzani, R. A review of the mandibular and maxillary nerve supplies and their clinical relevance. Arch. Oral Biol., 57(4):323-34, 2012.

Rouas, P.; Nancy, J. \& Bar, D. Identification of double mandibular canals: literature review and three case reports with CT scans and cone beam CT. Dentomaxillofac. Radiol., 36(1):34-8, 2007. 
DE CASTRO, M. A. A.; VICH, M. O. L.; ABREU, M. H. G. \& MESQUITA, R. A. Cross-sectional study of mandibular canal branching in regions affected by dental inflammation with cone beam computed tomography. Int. J. Odontostomat., 13(2):142-149, 2019.

Tyndall, D. A.; Price, J. B.; Tetradis, S.; Ganz, S. D.; Hildebolt, C.; Scarfe, W. C. \& American Academy of Oral and Maxillofacial Radiology. Position statement of the American Academy of Oral and Maxillofacial Radiology on selection criteria for the use of radiology in dental implantology with emphasis on cone beam computed tomography. Oral Surg. Oral Med. Oral Pathol. Oral Radiol., 113(6):817-26, 2012.

von Elm, E.; Altman, D. G.; Egger, M.; Pocock, S. J.; Gøtzsche, P. C.; Vandenbroucke, J. P. \& STROBE Initiative. Strengthening the Reporting of Observational Studies in Epidemiology (STROBE) statement: guidelines for reporting observational studies. B. M. J., 335(7624):806-8, 2007.

Wilson, S.; Johns, P. \& Fuller, P. M. The inferior alveolar and mylohyoid nerves: an anatomic study and relationship to local anesthesia of the anterior mandibular teeth. J. Am. Dent. Assoc., 108(3):350-2, 1984.
Corresponding author:

Mauricio Augusto Aquino de Castro

Department of Dentistry

Federal University of Juiz de Fora

Campus Governador Valadares

Avenida Dr. Raimundo Monteiro Rezende, 330, Centro Governador Valadares/MG

BRAZIL

E-mail: mauricioaacastro@gmail.com

Received: 20-09-2018

Accepted: 28-01-2019 